\title{
Experimental and Numerical Study of the Interfacial Shear Strength in Carbon Fiber/Epoxy Resin Composite under Thermal Loads
}

\author{
Hongxiao Wang $\mathbb{D},{ }^{1}$ Xiaohui Zhang $\mathbb{D}^{1},{ }^{1}$ Yugang Duan, ${ }^{1}$ and Lingjie Meng ${ }^{2}$ \\ ${ }^{1}$ School of Mechanical Engineering, State Key Laboratory for Manufacturing Systems Engineering, \\ Xian Jiaotong University, 99 Yanxiang Road, Xian, Shaanxi 710054, China \\ ${ }^{2}$ School of Chemical Engineering and Technology, Xian Jiao Tong University, 28 West Xianning Road, Xian, Shaanxi 710049, China \\ Correspondence should be addressed to Xiaohui Zhang; xarzxh@163.com
}

Received 13 October 2017; Revised 26 December 2017; Accepted 23 January 2018; Published 15 February 2018

Academic Editor: Qi Shen

Copyright (C) 2018 Hongxiao Wang et al. This is an open access article distributed under the Creative Commons Attribution License, which permits unrestricted use, distribution, and reproduction in any medium, provided the original work is properly cited.

This study examined the influence mechanism of temperature on the interfacial shear strength (IFSS) between carbon fiber (CF) and epoxy resin (EP) matrices under various thermal loads using experimental and numerical simulation methods. To evaluate the change in IFSS as a function of the increase in temperature, a microbond test was performed under controlled temperature environment from $23^{\circ} \mathrm{C}$ to $150^{\circ} \mathrm{C}$. The experimental results showed that IFSS values of $\mathrm{CF} / \mathrm{EP}$ reduce significantly when the temperature reaches near glass transition temperature. To interpret the effect of thermal loads on IFSS, a thermal-mechanical coupling finite element model was used to simulate the process of fiber pull-out from EP. The results revealed that temperature dependence of IFSS is linked to modulus of the matrix as well as to the coefficients of thermal expansion of the fiber and matrix.

\section{Introduction}

The interface between fiber and matrix plays an important role in fiber-reinforced composite materials by affecting directly the load transfer efficiency between the fiber and the matrix as well as the mechanical properties of the composites $[1,2]$. The interfacial shear strength (IFSS) is a key parameter that influences the adhesion performance between the fiber and matrix $[3,4]$. However, because of the heat instability of EP $[5,6]$ and the significant difference between the fiber and the EP matrix [7], IFSS becomes unstable as it is affected by the curing process as well as service temperature [8].

The coefficients of thermal expansion (CLTE) of EP matrices are almost 100 times higher than the longitudinal thermal expansion coefficient of $\mathrm{CF}$ and 10 times greater than the transverse thermal expansion coefficient of CF by absolute value. These differences cause residual thermal stress at the interface during the cooling process [9-11]. As a result, tremendous efforts have been devoted to overcoming these problems. For example, Sockalingam et al. [12] developed a finite element modeling methodology to simulate the residual thermal stress with large CLTE mismatch between the fiber and the matrix caused by the cooling process. Also, Di Landro and Pegoraro [13] investigated the influence of the processing temperature and cooling rates on the residual stress in polymer composite matrices. They proposed that the residual thermal stress is mainly caused by the mismatch of CLTE between the fiber and matrix that importantly contributes to the fiber-matrix adhesion. Choo et al. [14] studied thermal path-dependency in the stress evolution of continuous-fiberreinforced composites by comparing cooling and reheat cycles. Their results showed that the effect of time-dependent deformation becomes more significant as the fiber content increases and cooling/heating rate reduces. However, most of the above-mentioned studies mainly focus on the influence of the curing process of IFSS; only a handful of studies were devoted to investigating cured CF/EP service under elevated temperature work conditions.

In fact, IFSS also changed with serviced temperature. For example, Thomason and Yang [15] explored the temperature dependence of IFSS in glass fiber polypropylene composites (GF-PP) and noticed that IFSS in GF-PP is inversely dependent on the testing temperature with a major increase 


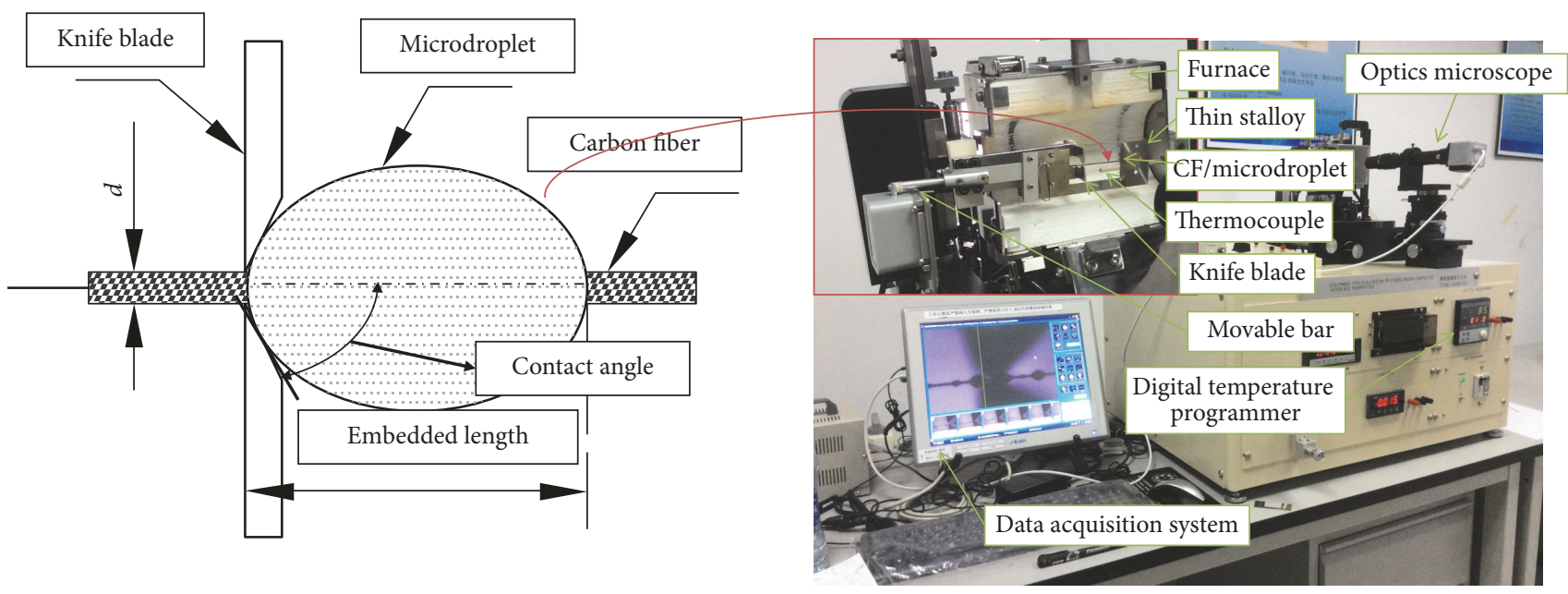

FIGURE 1: Temperature dependence HM410-microdroplet test equipment.

in glass transition region of the PP matrix. In their other paper [16], they found that the magnitude of the thermal residual stress due to mismatch in the thermal expansion coefficients of fiber and matrix was insufficient to explain the magnitude of the system IFSS, and they suggest that the residual stress combined with static adhesion could be the major contributor to the apparent interfacial adhesion in glass fiber-epoxy system, but they did not consider the effects of the temperature of resin on IFSS. In order to develop improved process ability and equipment operating at high temperature, Wang et al. [17] studied the thermal stability of carbon nanotube/epoxy nanocomposite by mechanical and interfacial evaluation at room temperature and $150^{\circ} \mathrm{C}$. The results show that addition of low concentration CNT could improve the thermal stability of epoxy resin in turn hence the IFSS under high temperature. Also, the similar conclusions had been reached in similar studies [18]. So, when cured $\mathrm{CF} / \mathrm{EP}$ service is under changing temperature work conditions, both the mismatch of CLTE between the fiber and matrix and the dependence-temperature of resin will cause a change in IFSS, hence affecting the CFRP performance. As a result, studying the mechanism of the influence of temperature on the interfacial properties of cured composites is of great importance.

The aim of this paper is to investigate the mechanism due to the influence of temperature on the interfacial properties of cured CFRP. In order to get the temperature dependence of IFSS, a microbond test was performed under controlled temperature; thermomechanical property tests were performed to get the Tg and the CLTE of resin matrix; tensile test was performed to measure the value of modulus changed with temperature. Furthermore, a FEM was developed to simulate the process of the microbond test under thermal loads to facilitate interpretation of the experiment observations. The FE analysis was carried out following three steps: (i) application of thermal preload and large mismatch in CTE between CF and EP to analyze the residual thermal stress due to the cooling process, (ii) modeling of the thermal stress in $\mathrm{CF} / \mathrm{EP}$ under thermal preload through changes from room to the working temperature, and (iii) modeling the process of single fiber pull-out from the microdroplet using the prestress of both residual thermal and thermal stresses.

\section{Experimental}

2.1. Materials and Test Sample. The EPs named TF1408 were obtained, respectively, from Hengshen Co. Ltd. Carbon fibers T300 were purchased from Toray Industries, Inc. The single CF was bonded on a thin stalloy adhered through microdroplet uncured EPs (Figure 1). All the samples were cured at $135^{\circ} \mathrm{C}$ and kept for 90 minutes in an oven, with the same heating rate and cooling rate of $3^{\circ} \mathrm{C} / \mathrm{min}$.

2.2. Microbond Testing. The temperature dependence of CF/EP IFSS was measured by HM410-microdroplet test equipment from TOHEI SANGYO, Japan (Figure 1). The temperature was automatically controlled and monitored through a digital temperature programmer. Five tests were performed at room temperature (RT), 60, 90, and $120^{\circ} \mathrm{C}$.

The required force to pull out the fiber of cured epoxy resin is measured for each specimen and the interfacial shear strength $\tau_{\text {IFSS }}$ was estimated by $[19,20]$

$$
\tau_{\mathrm{IFSS}}=\frac{F_{\max }}{\pi \cdot d_{f} \cdot l_{e}},
$$

where $F_{\max }$ is the maximum value of pull-out force, $d_{f}$ is the diameter of single fiber, and $l_{e}$ is the embedded length of microdroplet. However, since at the moment when $F=F_{\max }$ the crack length is not zero and the measured $F_{\max }$ value includes the contributions of interfacial adhesion and friction, the value of $\tau_{\text {IFSS }}$ calculated by (1) is the apparent IFSS.

The diameter of CF utilized in this study was $7 \mu \mathrm{m}$. For a big effect of specimen dimensions on the pull-out force and IFSS, the embedded length of EP microdroplet was maintained at $70-90 \mu \mathrm{m}$ and the contact angle at $40-45^{\circ} \mathrm{C}$ (Figure 1). The load-displacement curve from each test was recorded to obtain the maximum force $\left(F_{\max }\right)$ and a typical example is shown in Figure 2, where $F_{d}$ is kink force [21]; when the pull-out force reaches this value, the fiber begins to debond from the matrix; $F_{\max }$ is the peak force caused 


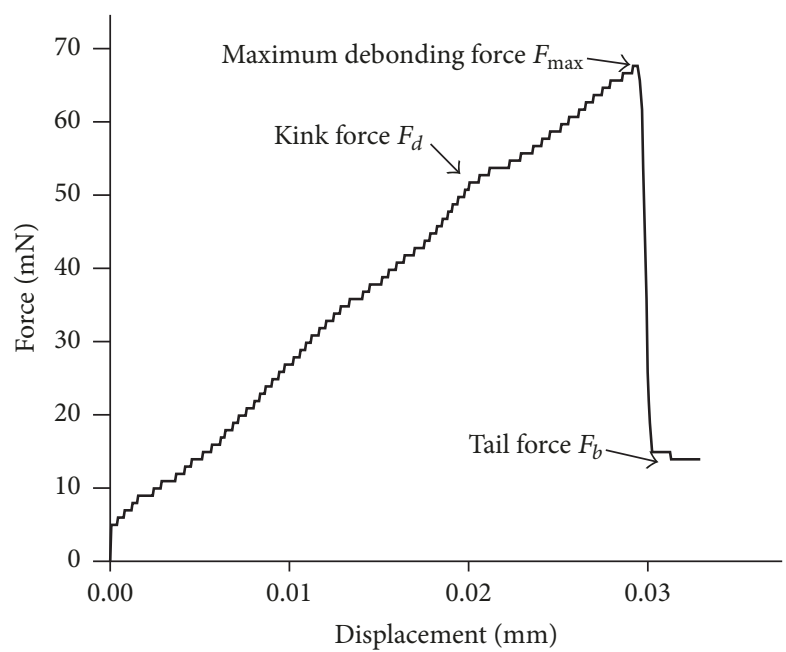

FIGURE 2: Load-displacement curve for the microdroplet test.

by debonding force and the frictional load in debonding regions; $F_{b}$ is the tail force caused by frictional load when the embedded fiber totally debond from the matrix.

2.3. Thermomechanical Property Tests. The thermomechanical properties of EPs were tested by dynamic mechanical analysis (DMA) and thermal expansion analysis [22]. A dynamic mechanical analyzer (DMA Q800) was used for measurement of the glass transition temperature $\left(T_{g}\right)$ as well as modulus versus temperature curve of both cured EPs. DMA tests were conducted using three-point bending modes (ASTM D5023-15) as it can provide the most analogous approach to normal mechanical testing method [23]. According to ASTM D5023-15, the dimensions utilized for DMA tests were $(60 \times 13 \times 3 \mathrm{~mm})$ and temperature scanning measurements were performed from $20^{\circ} \mathrm{C}$ to $150^{\circ} \mathrm{C}$ at a heating rate of $3^{\circ} \mathrm{C} / \mathrm{min}$ and an oscillation frequency of $1 \mathrm{~Hz}$. To ensure that measured temperature range includes the temperature of $T_{g}$, the real temperature sweep test was performed from $0^{\circ} \mathrm{C}$ to $200^{\circ} \mathrm{C}$. According to ASTM E289, the coefficient of the linear thermal expansion (CLTE) of EPs was measured using a dilatometer (DIL402C) from $20^{\circ} \mathrm{C}$ to $150^{\circ} \mathrm{C}$ at a heating rate $5^{\circ} \mathrm{C} / \mathrm{min}$ for CLTE test specimens of $(25 \times 5 \times 5 \mathrm{~mm})$.

2.4. Tensile Testing of Epoxy Resin. The moduli changed with different temperature were tested by this test. The temperature dependence of resin under tensile loading was determined using a universal testing machine (CMT4304; MTS, USA) according to the ASTM D638-10 "Standard Test Method for Tensile Properties of Plastics." The dumbbellshaped samples (type I) were stretched using an extensometer at a rate of $2 \mathrm{~mm} / \mathrm{min}$ and stress-strain curves were recorded for ambient temperatures ranging from RT to $120^{\circ} \mathrm{C}$ (at $30^{\circ} \mathrm{C}$ intervals) within the climatic chamber. For each condition, 5 tests were performed.

\section{Numerical Simulations Procedures}

3.1. Finite Element Modeling. Commercial finite element software Abaqus $^{@}$ (version 6.10) was utilized to carry out
TABle 1: Matrix properties at room temperature used for the numerical simulations.

\begin{tabular}{lcccc}
\hline Test temperature & $\mathrm{RT}$ & $60^{\circ} \mathrm{C}$ & $90^{\circ} \mathrm{C}$ & $120^{\circ} \mathrm{C}$ \\
\hline $\begin{array}{l}\text { Young's modulus, } E_{m} \\
(\mathrm{MPa})\end{array}$ & 3960 & 3068 & 2510 & 1590 \\
$\begin{array}{l}\text { Poisson's ratio } \\
\begin{array}{l}\text { Coefficient of thermal } \\
\text { expansion }\left(10-6 /{ }^{\circ} \mathrm{C}\right)\end{array}\end{array}$ & 0.37 & 0.37 & 0.37 & 0.37 \\
\hline
\end{tabular}

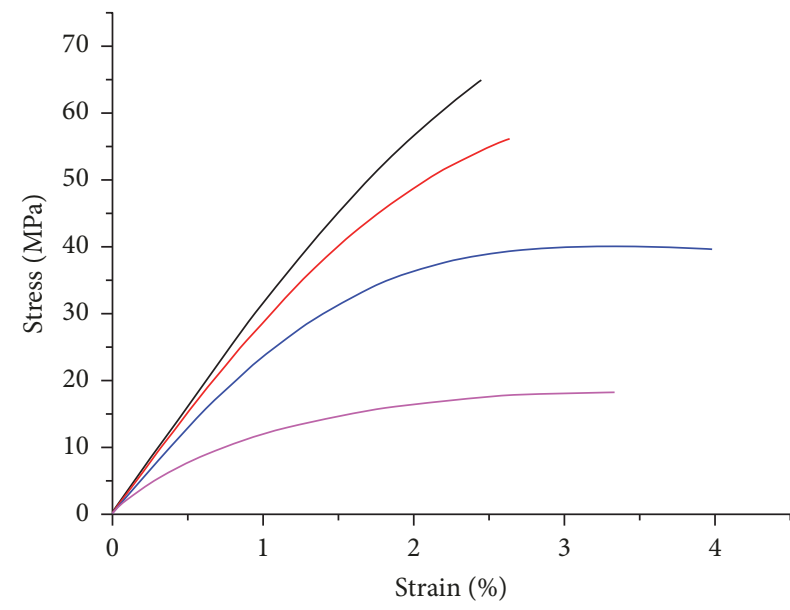

$\begin{array}{ll}\text { Ambient temperature } & \\ -23^{\circ} \mathrm{C} & -90^{\circ} \mathrm{C} \\ -60^{\circ} \mathrm{C} & -120^{\circ} \mathrm{C}\end{array}$

FIGURE 3: Representative stress-strain curves of the epoxy resin under different temperature conditions.

FE calculations. The baseline FE model of the microbond test consists of a single CF with a diameter of $7 \mu \mathrm{m}$ and an epoxy matrix droplet with embedded length of $80 \mu \mathrm{m}$ made by eight-node fully integrated solid elements. The matrix was modeled as an isotropic elastic material with properties shown in Table 1. Here, Young's modulus of resin was the slope of stress-strain curves under linear-elastic range and measured by tensile tests (Figure 3); the thermal expansion of resin under different temperatures was measured by CLTE tests (Figure 4). The fiber was modeled as an orthotropic elastic material with properties shown in Table 2 [24]. The knife blade was modeled as a rigid body and owing to its symmetry, only a quarter of the fiber and droplet were modeled (Figure 5).

3.2. Interfacial Behavior. The fiber-matrix interphase is subjected to the cohesive force and the residual compressive radial force, which results in a sliding friction force in the process of interfacial debonding. So in this study, the interfacial was model with cohesive element and coulomb friction contact behavior.

The zero thickness cohesive elements with a mixed-mode traction-separation law [25] (Figure 6) was used to model the process of interface debonding. The failure model of traction-separation used in this study is quadratic stress failure criterion [26] and a Benzeggagh-Kenane (BK) criterion [27] to evaluate, respectively, both the initial damage and 


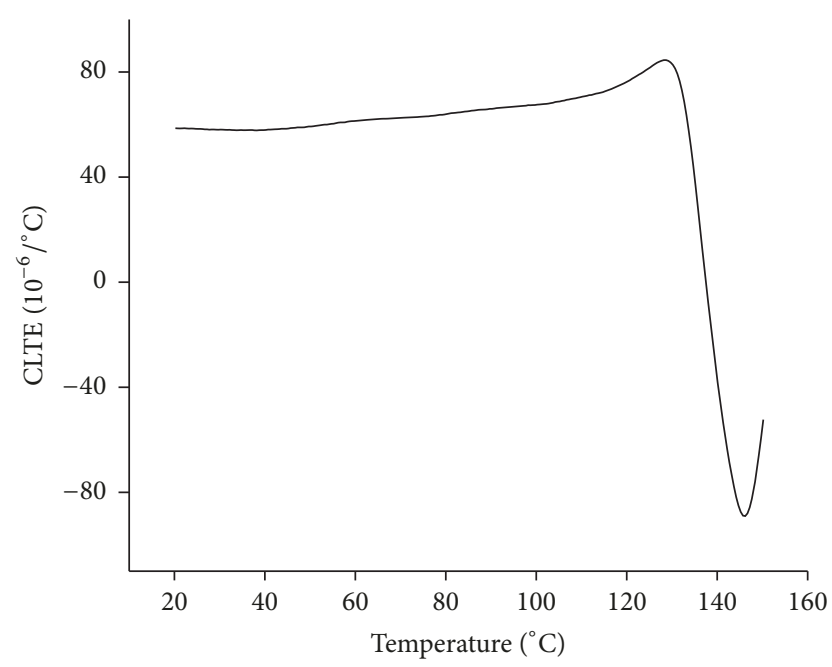

Figure 4: Coefficient of thermal expansion of epoxy resin versus temperature.

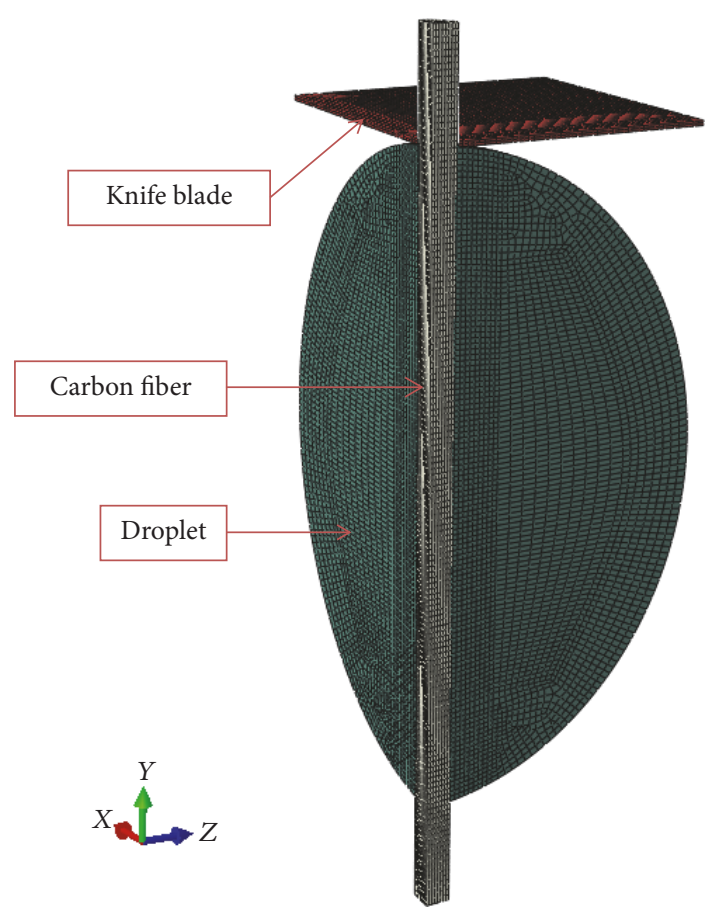

FIGURE 5: Quarter symmetric FEM of the microdroplet test.

crack propagation. The quadratic stress failure criterion was expressed through

$$
\left(\frac{\max \left\langle\sigma_{n}, 0\right\rangle}{N_{\max }}\right)^{2}+\left(\frac{\sigma_{t}}{T_{\max }}\right)^{2}+\left(\frac{\sigma_{s}}{S_{\max }}\right)^{2}=1,
$$

where $\sigma_{n}, \sigma_{s}$, and $\sigma_{t}$ are the stress components of, respectively, pure normal direction, first shear direction, and second shear direction. $N_{\max }, S_{\max }$, and $T_{\max }$ are the interfacial strengths of, respectively, pure normal direction, first shear direction, and second shear direction. The stiffness coefficient of cohesive element is estimated using the peak stress and the maximum relative experimental displacement by the results of microbond test. The BK criterion for crack propagation can be evaluated through [27]

$$
G_{\mathrm{IC}}+\left(G_{\mathrm{IIC}}-G_{\mathrm{IC}}\right)\left\{\frac{G_{\mathrm{II}}+G_{\mathrm{III}}}{G_{\mathrm{I}}+G_{\mathrm{II}}+G_{\mathrm{III}}}\right\}^{\eta}=G_{C}
$$

where $G_{i}$ and $G_{i C}(i=$ I, II, III $)$ are the corresponding strain energy release rates and fracture toughness under, respectively, pure mode I, mode II, and mode III loadings. $G_{C}=G_{I}+G_{I I}+G_{I I I}$ is the fracture toughness, and $\eta$ is the BK exponent. Fracture toughness $G_{i C}$ is estimated using the kink force $F_{d}$ issued from microdroplet test at stress-free temperature through [28]

$$
G_{i C}=\frac{r C_{33 s}}{2}\left[\frac{F_{d}}{\pi r^{2}}+\frac{\left(\alpha_{A}-\alpha_{m}\right) \Delta T}{2 C_{33 s}}\right]^{2},
$$

where $F_{d}$ is the kink force measured from microbond test, $r$ is the radius of the fiber, and $\alpha_{A}$ and $\alpha_{m}$ are, respectively, the axial coefficient for thermal expansion of the fiber and the matrix. $\Delta T$ is the difference between the test and stress-free temperatures and $C_{33 s}$ is given by

$$
C_{33 s}=\frac{1}{2}\left[\frac{1}{E_{A}}+\frac{V_{1}}{V_{2} E_{m}}\right],
$$

where $E_{A}$ and $E_{m}$ are, respectively, the fiber axial modulus and matrix tensile modulus. $V_{1}$ and $V_{2}$ are volume fractions of the fiber and the matrix, respectively. In this study, the traction law for mode I is assumed to be the same as modes II and III.

A coulomb friction is used to model the friction caused by residual compressive radial force. The coefficient of friction during progressive debonding is estimated by the ratio of tail force $F_{b}$ tested by the results of microbond test (Figure 2) and the radial force caused by the residual thermal stress.

3.3. Residual Thermal Stress Analysis. The residual stresses due to thermal shrinkage during cooling down from the cure temperature to room temperature were simulated by application of thermal preload to the FE model. A thermal preload was applied using $T_{g}$ as stress-free temperature and the operating temperature as room temperature $\left(23^{\circ} \mathrm{C}\right) . T_{g}$ of the epoxy resin was commonly used to define the stressfree temperature in calculation of the residual stress [29]. The model of the knife blade was suppressed in this step and instead an axisymmetric loading was applied to the matrix droplet and fiber. The mixed-mode damage and crack initiation loads were set on the fiber-matrix interphase.

3.4. Thermal Stress Analysis. The thermal stress analysis due to thermal preload was simulated under a prestress of residual thermal stress. A thermal preload was set on the fiber and matrix from room to working temperatures and Young's modulus of the matrix was modified to the corresponding temperature. The model of the knife blade was suppressed in this step too and axisymmetric loading was applied to the matrix droplet and the fiber. A mixed-mode damage and crack initiation loads were set on the fiber-matrix interphase. 


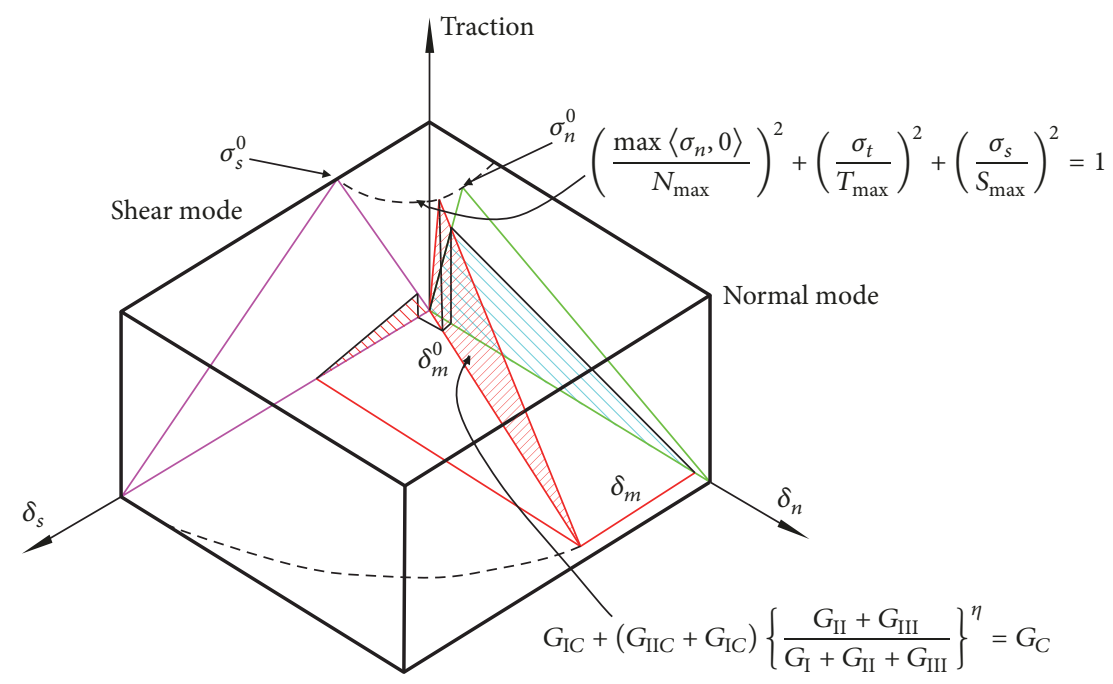

FIGURE 6: Mixed-mode traction-separation law.

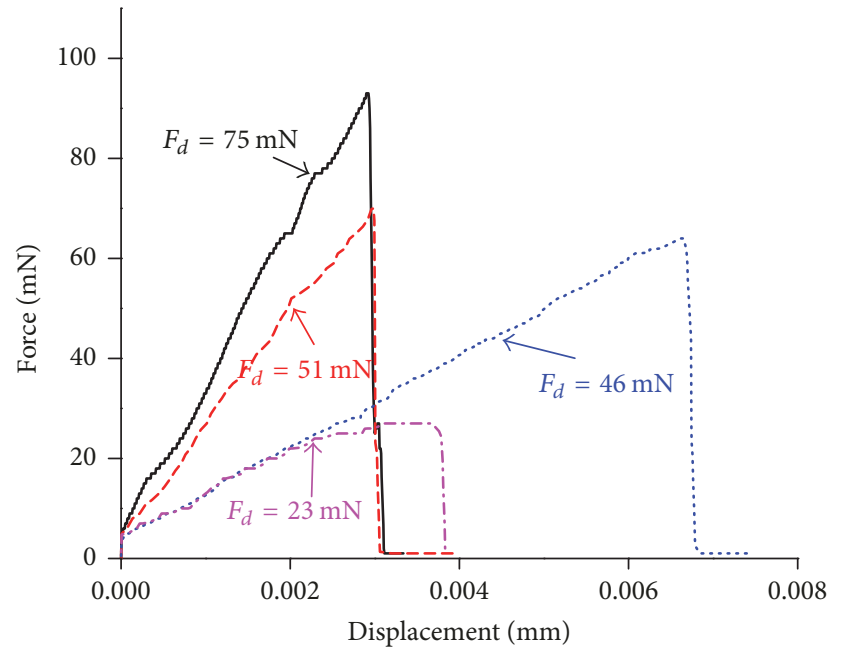

Test temperature

$$
-23^{\circ} \mathrm{C} \quad \cdots \cdots 90^{\circ} \mathrm{C}
$$

FIGURE 7: Force-displacement curves under different tested temperature by experiment results.

3.5. Microdroplet Debonding Analysis. The process of single fiber pull-out from the microdroplet was modeled under the prestress of residual thermal and thermal stresses. The knife blade was activated and fixed boundary conditions were applied to the knife blade. A contact property was set between the knife blade and droplet and constant displacement loading was applied to the fiber along the axial direction. An axisymmetric loading was applied to the matrix droplet and fiber and mixed-mode damage and crack initiation loads were set on the fiber-matrix interphase.

\section{Results and Discussion}

Figure 7 shows the force-displacement curve of microbond test under different temperature; the results show that the peak forces are decreased with tested temperature increasing.

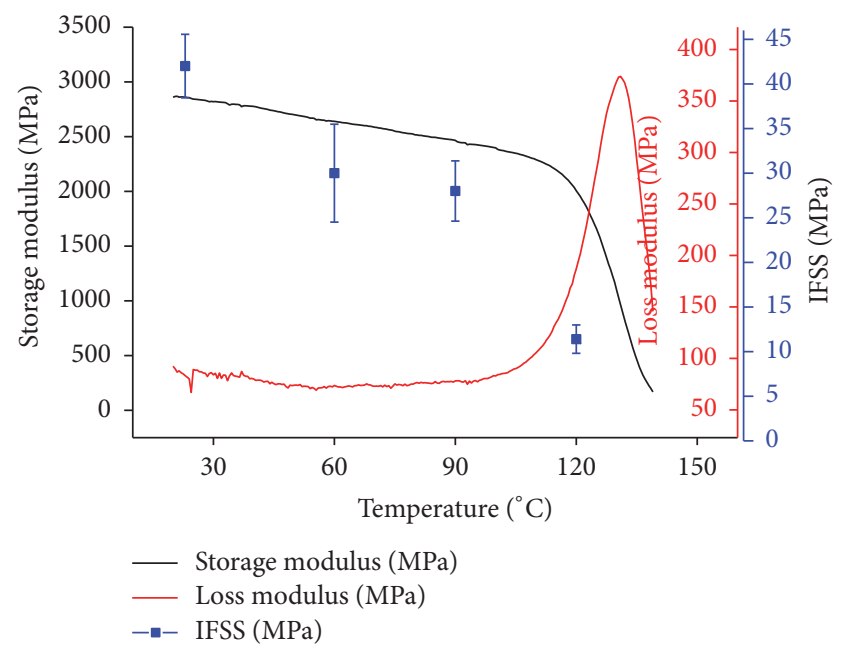

FIGURE 8: EPs matrix storage/loss modulus and apparent IFSS versus temperature.

Correspondently, the apparent IFSS also decreased with tested temperature increasing. Figure 8 illustrates results from the thermomechanical characterization of EPs obtained through DMA and apparent IFSS as a function of temperature. It can clearly be seen that the measured apparent IFSS for CF/EP is significantly affected by the thermal load, where apparent IFSS decreases substantially near $T_{g}$. Also, the change point of apparent IFSS decrease with temperature (about $120-130^{\circ} \mathrm{C}$ from Figure 8 ) is approximately equal to $T_{g}$ of EPs (about $123-131^{\circ} \mathrm{C}$ from Figure 8).

Figure 9 depicts results from the process of fiber pullout performed at three different temperatures, which further confirmed the effect of temperature on the apparent IFSS. It is clear that failure modes of the fiber pull-out significantly change as temperature increases. At processing temperatures below $T_{g}$, increasing the pull-out force induces a crack that propagates along the interface between the fiber and the matrix, where the droplet will be in complete debonding with 


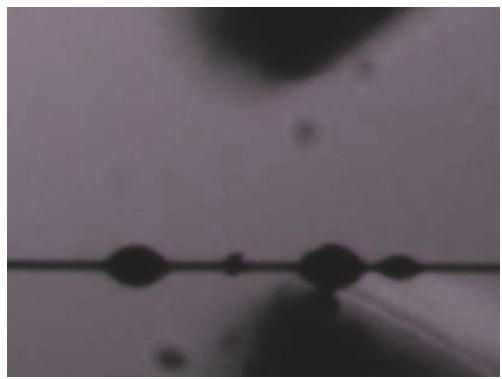

(a)

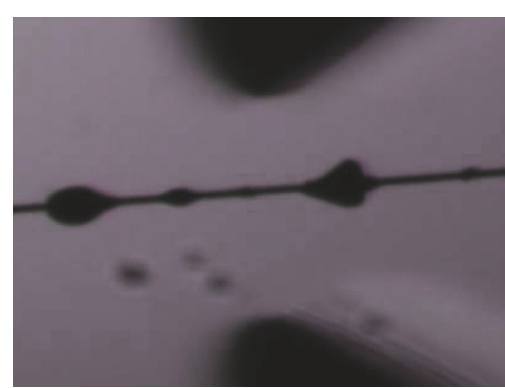

(b)

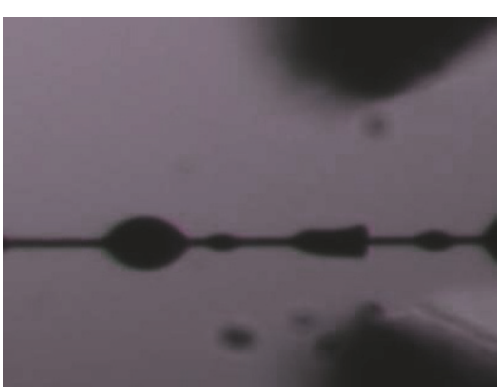

(c)

FIGURE 9: The process of fiber outperformed at different temperatures: (a) temperature $<T_{g}$; (b) temperature near to $T_{g}$; and (c) temperature $>T_{g}$.

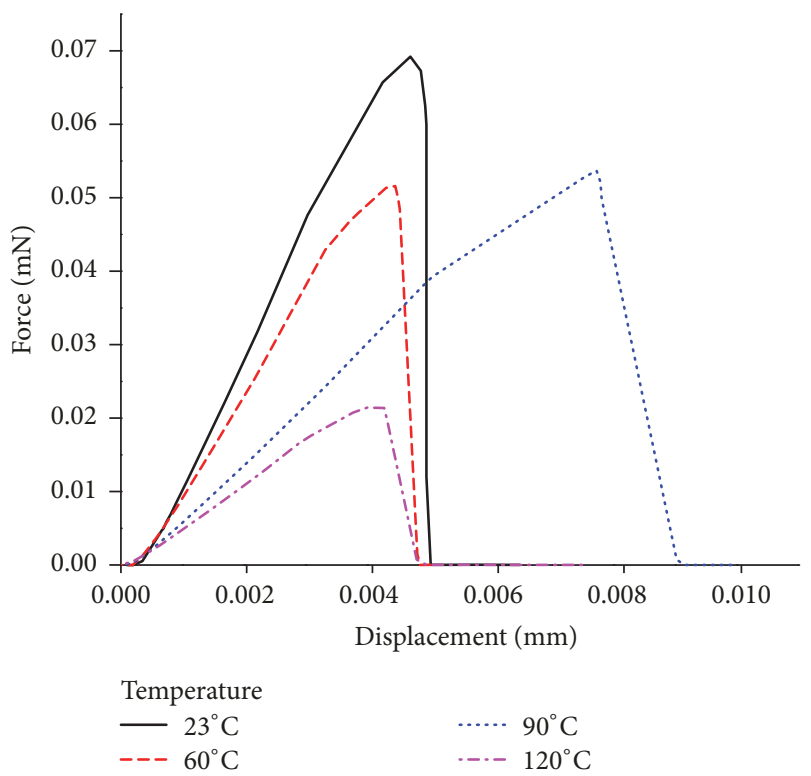

Figure 10: Simulated force-displacement curves under different temperature.

very little deformation (Figure 9(a)). When the processing temperature reaches $T_{g}$, the stiffness of EP reduces as the pullout force increases. This induces the droplet to completely debond with larger deformation effect (Figure 9(b)). At processing temperature above $T_{g}$, modulus of EP becomes particularly weak due to the relaxation transition in the polymer. As the apparent IFSS is larger than EP, failure will be induced in EP (Figure 9(c)).

However, the above experiment results just proved the effect of temperature on the fiber pull-out peak force and apparent IFSS, the effect mechanism of the thermal stress and modulus on the apparent IFSS cannot be observed from the experiment results. So, it is necessary to analyze this question by finite element analysis. For the different fracture toughness, peak stress, stiffness coefficient of cohesive element, and the different modulus and CLET of resin matrix under 23, 60,90 , and $120^{\circ} \mathrm{C}$ were predicted by models with the same traction laws as shown in Figure 10. The values of apparent IFSS calculated by the peak force of the experiment and
TABLE 2: Carbon fiber properties at room temperature used for the numerical simulations.

\begin{tabular}{lc}
\hline Elastic properties & Carbon fiber \\
\hline Longitudinal stiffness, $E_{11}(\mathrm{MPa})$ & 233130 \\
Transverse stiffness, $E_{22}(\mathrm{MPa})$ & 23110 \\
Out-of-plane stiffness, $E_{33}(\mathrm{MPa})$ & 23110 \\
Poisson's ratio, $v_{12}$ & 0.2 \\
Poisson's ratio, $v_{13}$ & 0.2 \\
Poisson's ratio, $v_{23}$ & 0.4 \\
Shear modulus, $G_{12}(\mathrm{MPa})$ & 8960 \\
Shear modulus, $G_{13}(\mathrm{MPa})$ & 8960 \\
Shear modulus, $G_{23}(\mathrm{MPa})$ & 8270 \\
Coefficient of thermal expansion $\alpha_{1}\left(10-6 /{ }^{\circ} \mathrm{C}\right)$ & -0.54 \\
Coefficient of thermal expansion $\alpha 2\left(10-6 /{ }^{\circ} \mathrm{C}\right)$ & 10.10 \\
\hline
\end{tabular}

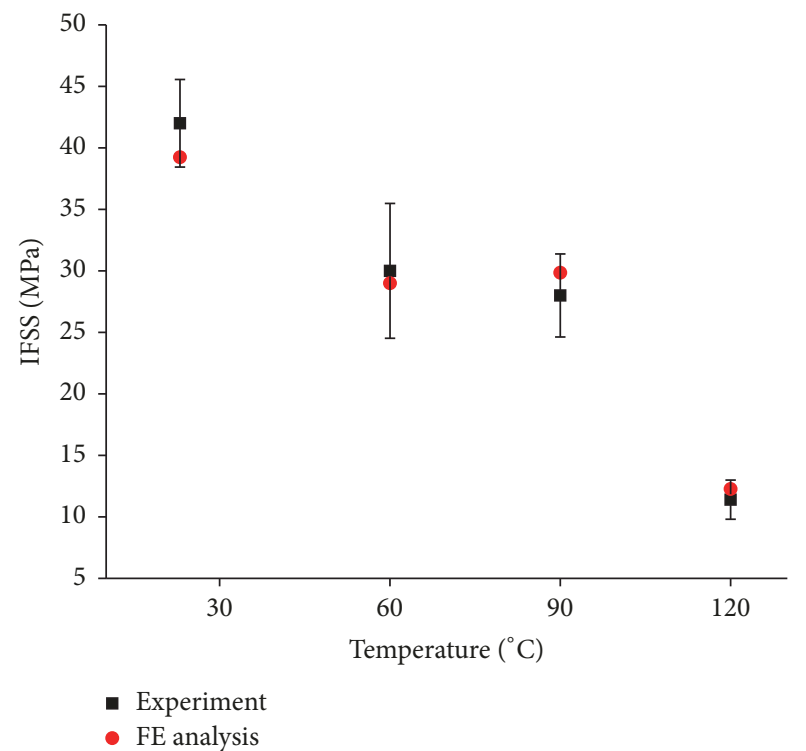

FIGURE 11: Comparison of apparent IFSS between the simulated and experimental data.

simulations are shown in Figure 11. It is clear from Figures 8 and 10 that, although there is still error, the trend of forcedisplacement curves of FE models is in good agreement with 


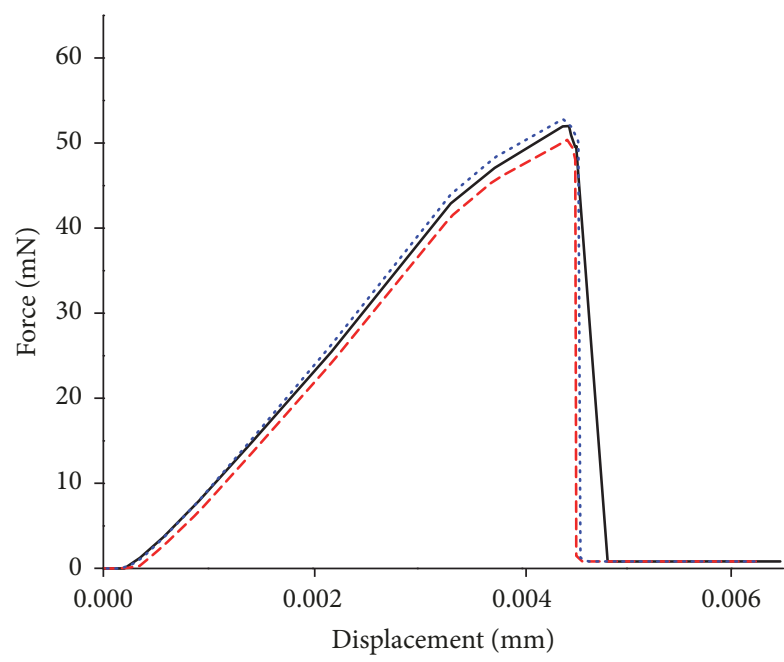

- With $60^{\circ} \mathrm{C}$ thermal stress, $E_{m}=3068 \mathrm{MPa}$
--- With $60^{\circ} \mathrm{C}$ thermal stress, $E_{m}=3960 \mathrm{MPa}$
$\ldots$ No thermal stress, $E_{m}=3068 \mathrm{MPa}$

(a)

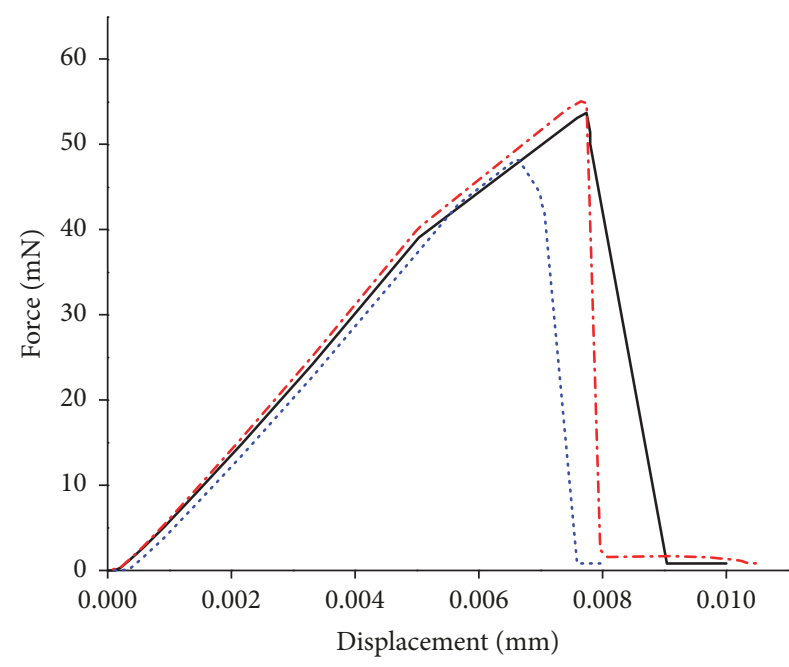

With $90^{\circ} \mathrm{C}$ thermal stress, $E_{m}=2510 \mathrm{MPa}$
-..- With $90^{\circ} \mathrm{C}$ thermal stress, $E_{m}=3068 \mathrm{MPa}$
.... No thermal stress, $E_{m}=2510 \mathrm{MPa}$

(b)

FIGURE 12: Simulated force-displacement curves for the effect of CLET and EP's modulus (a) under $60^{\circ} \mathrm{C}$ and (b) under $90^{\circ} \mathrm{C}$.

the experimental results. And the value of apparent IFSS by $\mathrm{FE}$ analysis is in the error range of experimental data.

The results for the same fracture toughness, peak stress, stiffness coefficient of cohesive element with different modulus of EP, and thermal stress under 60 and $90^{\circ} \mathrm{C}$ are gathered in Figures 12(a) and 12(b). It can be observed from Figure 12 that the thermal stress caused by the mismatch of CLTE under higher temperature can increase the peak force; on the contrary, the peak forces are decreasing with the modulus of resin matrix under higher temperature. So, the temperature dependence of CF/EP IFSS was also linked to the thermal stress caused by the mismatch of CLTE and the modulus of resin matrix. Due to the mismatch of CLTE, the IFSS is increased with temperature increasing and is decreased in Young's modulus with temperature increasing. For the trend of IFSS is decreased with the temperature increasing in this study, the effect of the thermal stress caused by the mismatch of CLTE is lower than the modulus of matrix with temperature increasing.

\section{Conclusions}

The effects of temperature on the interfacial properties of $\mathrm{CF} / \mathrm{EP}$ were investigated through a microbond test under controlled temperature environment. The experimental results revealed that apparent IFSS for CF/EP at temperatures below that of glass transition of EP does not show a significant decrease. However, this becomes significantly reduced at higher temperatures than that of glass transition. To interpret the experimental results, a series of FE calculations were carried out to simulate the process of microbond test as a function of the thermal loads. The results show that the thermal stress caused by the mismatch of CLTE under higher temperature can increase the peak force and apparent
IFSS; oo the contrary, the peak forces are decreasing with the modulus of resin matrix under higher temperature. The effect of the thermal stress caused by the mismatch of CLTE is lower than the modulus of matrix with temperature increasing.

\section{Conflicts of Interest}

The authors declare that there are no conflicts of interest regarding the publication of this paper.

\section{Acknowledgments}

The authors acknowledge the financial support by "the Fundamental Research Funds for the Central Universities" (no. xjj201760).

\section{References}

[1] R. Minty, J. Thomason, and H. Petersen, The Role of The Epoxy Resin: Curing Agent Ratio in Composite Interfacial Strength by Single Fibre Microbond Test, 2015.

[2] H. Li, Y. Wang, C. Zhang, and B. Zhang, "Effects of thermal histories on interfacial properties of carbon fiber/polyamide 6 composites: Thickness, modulus, adhesion and shear strength," Composites Part A: Applied Science and Manufacturing, vol. 85, pp. 31-39, 2016.

[3] K. M. Beggs, L. Servinis, T. R. Gengenbach, M. G. Huson, B. L. Fox, and L. C. Henderson, "A systematic study of carbon fibre surface grafting via in situ diazonium generation for improved interfacial shear strength in epoxy matrix composites," Composites Science and Technology, vol. 118, pp. 31-38, 2015.

[4] B. Liu, Z. Liu, X. Wang, G. Zhang, S. Long, and J. Yang, "Interfacial shear strength of carbon fiber reinforced polyphenylene sulfide measured by the microbond test," Polymer Testing, vol. 32, no. 4, pp. 724-730, 2013. 
[5] O. Zabihi, H. Khayyam, B. L. Fox, and M. Naebe, "Enhanced thermal stability and lifetime of epoxy nanocomposites using covalently functionalized clay: Experimental and modelling," New Journal of Chemistry, vol. 39, no. 3, pp. 2269-2278, 2015.

[6] G.-R. Xu, M.-J. Xu, and B. Li, "Synthesis and characterization of a novel epoxy resin based on cyclotriphosphazene and its thermal degradation and flammability performance," Polymer Degradation and Stability, vol. 109, pp. 240-248, 2014.

[7] Y. Pan and A. A. Pelegri, "Influence of matrix plasticity and residual thermal stress on interfacial debonding of a single fiber composite," Journal of Mechanics of Materials and Structures, vol. 5, no. 1, pp. 129-142, 2010.

[8] S.-L. Gao and J.-K. Kim, "Cooling rate influences in carbon fibre/PEEK composites. Part II: Interlaminar fracture toughness," Composites - Part A: Applied Science and Manufacturing, vol. 32, no. 6, pp. 763-774, 2001.

[9] A. E. Litherland and T. Le'H, “Transcrystallized interphase in thermoplastic composites. II: Influence of interfacial stress, cooling rate, fibre properties and polymer molecular weight," Journal of Materials Science, 1992.

[10] Y. Wang and T. H. Hahn, "AFM characterization of the interfacial properties of carbon fiber reinforced polymer composites subjected to hygrothermal treatments," Composites Science and Technology, vol. 67, no. 1, pp. 92-101, 2007.

[11] M. Zhu, M. Li, Q. Wu, Y. Gu, Y. Li, and Z. Zhang, "Effect of processing temperature on the micro- and macro-interfacial properties of carbon fiber/epoxy composites," Composite Interfaces, vol. 21, no. 5, pp. 443-453, 2014.

[12] S. Sockalingam, M. Dey, J. W. Gillespie Jr., and M. Keefe, "Finite element analysis of the microdroplet test method using cohesive zone model of the fiber/matrix interface," Composites Part A: Applied Science and Manufacturing, vol. 56, pp. 239-247, 2014.

[13] L. Di Landro and M. Pegoraro, "Evaluation of residual stresses and adhesion in polymer composites," Composites Part A: Applied Science and Manufacturing, vol. 27, no. 9, pp. 847-853, 1996.

[14] H. Choo, M. A. M. Bourke, and M. R. Daymond, "A finiteelement analysis of the inelastic relaxation of thermal residual stress in continuous-fiber-reinforced composites," Composites Science and Technology, vol. 61, no. 12, pp. 1757-1772, 2001.

[15] J. L. Thomason and L. Yang, “Temperature dependence of the interfacial shear strength in glass-fibre polypropylene composites," Composites Science and Technology, vol. 71, no. 13, pp. 1600-1605, 2011.

[16] J. L. Thomason and L. Yang, "Temperature dependence of the interfacial shear strength in glass-fibre epoxy composites," Composites Science and Technology, vol. 96, pp. 7-12, 2014.

[17] Z.-J. Wang, D.-J. Kwon, J.-Y. Choi et al., "Inherent and interfacial evaluations of carbon nanotubes/epoxy composites and single carbon fiber at different temperatures," Composites Part B: Engineering, vol. 91, pp. 111-118, 2016.

[18] K. Guru, S. B. Mishra, and K. K. Shukla, "Effect of temperature and functionalization on the interfacial properties of CNT reinforced nanocomposites," Applied Surface Science, vol. 349, pp. 59-65, 2015.

[19] F.-H. Zhang, R.-G. Wang, X.-D. He, C. Wang, and L.-N. Ren, "Interfacial shearing strength and reinforcing mechanisms of an epoxy composite reinforced using a carbon nanotube/carbon fiber hybrid," Journal of Materials Science, vol. 44, no. 13, pp. 3574-3577, 2009.
[20] E. Pisanova, S. Zhandarov, E. Mäder, I. Ahmad, and R. J. Young, "Three techniques of interfacial bond strength estimation from direct observation of crack initiation and propagation in polymer-fibre systems," Composites Part A: Applied Science and Manufacturing, vol. 32, no. 3-4, pp. 435-443, 2001.

[21] S. Zhandarov and E. Mäder, "Characterization of fiber/matrix interface strength: Applicability of different tests, approaches and parameters," Composites Science and Technology, vol. 65, no. 1, pp. 149-160, 2005.

[22] H. Watanabe, N. Yamada, and M. Okaji, "Linear thermal expansion coefficient of silicon from 293 to $1000 \mathrm{~K}$," International Journal of Thermophysics, vol. 25, no. 1, pp. 221-236, 2004.

[23] S. Deng, M. Hou, and L. Ye, “Temperature-dependent elastic moduli of epoxies measured by DMA and their correlations to mechanical testing data," Polymer Testing, vol. 26, no. 6, pp. 803813, 2007.

[24] M. W. Hyer and S. R. White, Stress Analysis of Fiber-Reinforced Composite Materials: WCB, McGraw-Hill, 1998.

[25] D. Systems, ABAQUS V 6103 Documentation, 2011.

[26] P. P. Camanho, C. G. Dávila, and M. F. De Moura, "Numerical simulation of mixed-mode progressive delamination in composite materials," Journal of Composite Materials, vol. 37, no. 16, pp. 1415-1438, 2003.

[27] M. L. Benzeggagh and M. Kenane, "Measurement of mixedmode delamination fracture toughness of unidirectional glass/epoxy composites with mixed-mode bending apparatus," Composites Science and Technology, vol. 56, no. 4, pp. 439-449, 1996.

[28] R. J. Scheer and J. A. Nairn, "A Comparison of Several Fracture Mechanics Methods for Measuring Interfacial Toughness with Microbond Tests," The Journal of Adhesion, vol. 53, no. 1-2, pp. 45-68, 1995.

[29] Y. Jia, W. Yan, and H.-Y. Liu, "Carbon fibre pullout under the influence of residual thermal stresses in polymer matrix composites," Computational Materials Science, vol. 62, pp. 7986, 2012. 


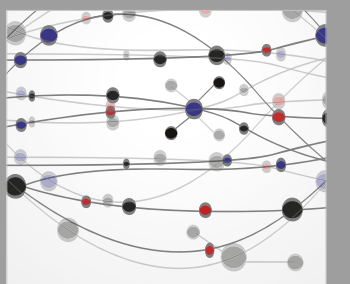

The Scientific World Journal
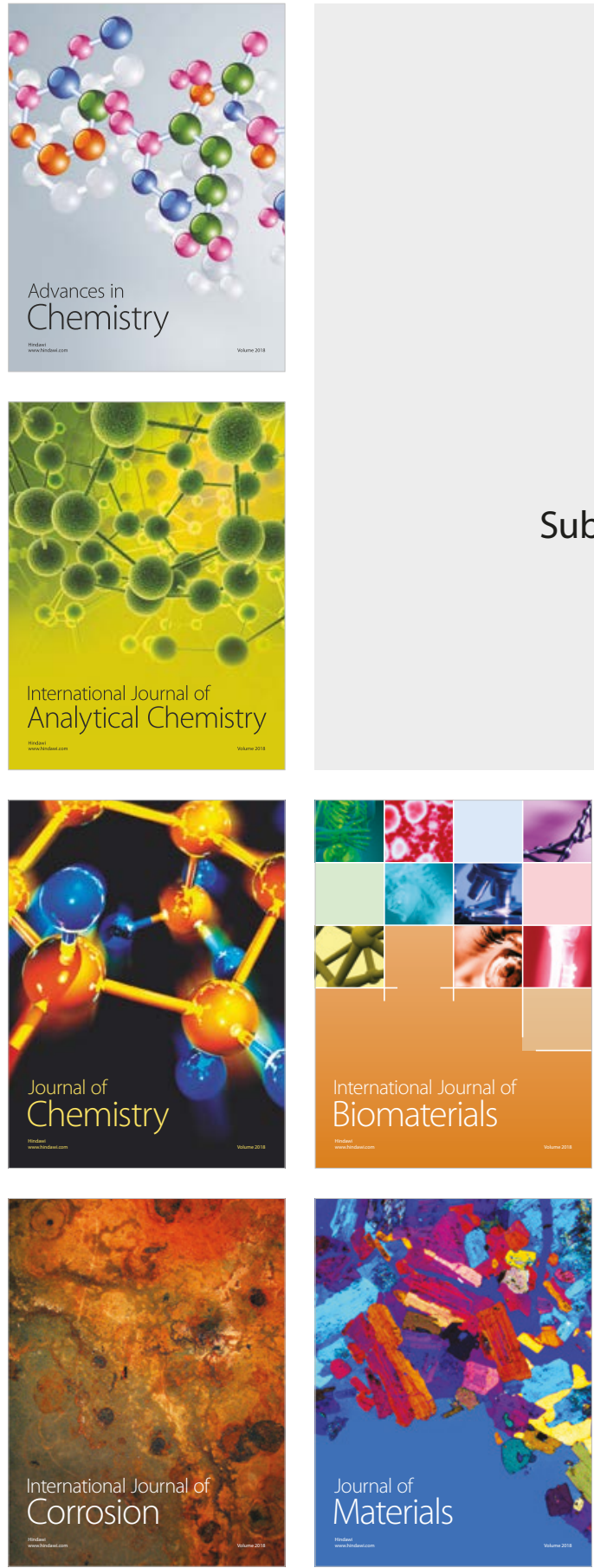

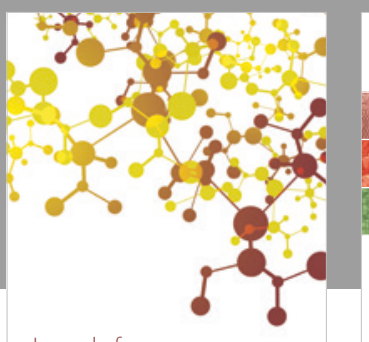

Journal of

Applied Chemistry
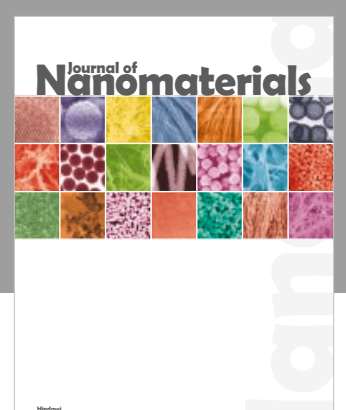

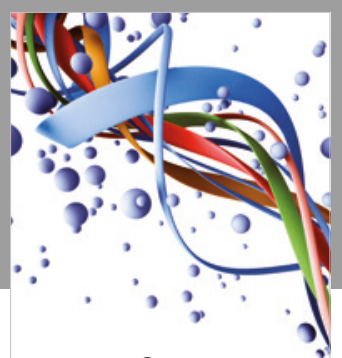

Scientifica

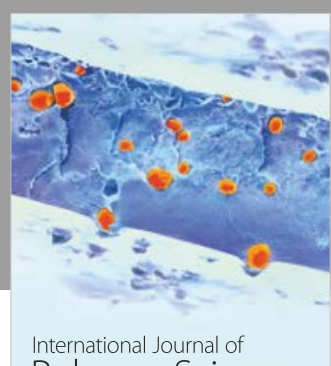

Polymer Science

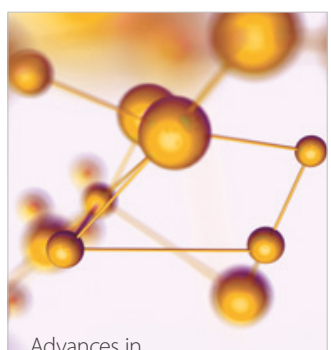

Physical Chemistry
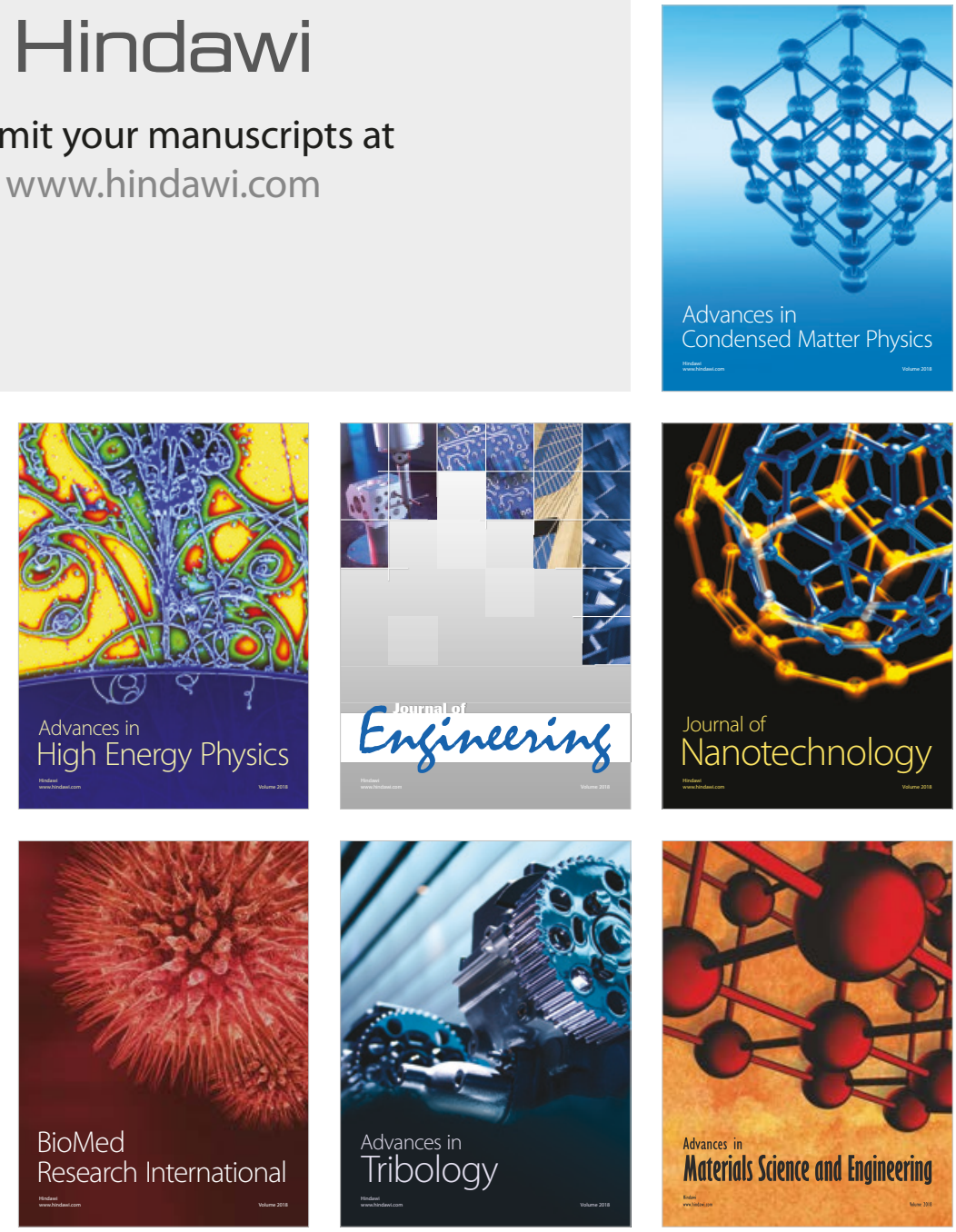